\title{
Effects of sulphasalazine (Salazopyrin) on faecal flora in patients with inflammatory bowel disease
}

\author{
BERYL WEST, R. LENDRUM ${ }^{1}$, M. J. HILL, AND GEOFFREY WALKER \\ From the Departments of Bacteriology and Gastroenterology, St Mary's Hospital, London
}

SUMmaRY The faecal flora of 21 patients with proctocolitis and five patients with Crohn's disease of the large bowel was examined both while sulphasalazine was being administered and during control periods. Patients with proctocolitis and Crohn's disease who were not receiving sulphasalazine had a similar flora which did not differ in any way from the normal. The effect of sulphasalazine was to decrease the numbers of opalescent-negative clostridia, enterobacteria, and total non-sporing anaerobes. It is suggested that this antibacterial effect of sulphasalazine, which has not been previously demonstrated, may be related to the beneficial effects of this drug in proctocolitis and should be investigated further.

Sulphasalazine (salicyl-azo-sulphapyridine, SASP) has been shown to be effective in the treatment of mild proctocolitis (Baron, Connell, Lennard-Jones, and Avery Jones, 1962; Dick, Grayson, Carpenter, and Petrie, 1964), and, more importantly, in the prevention of relapses of this disease (Misiewicz, Lennard-Jones, Connell, Baron, and Avery Jones, 1965; Dissanayake and Truelove, 1973). The metabolic pathways involved in SASP metabolism are now well established (fig 1) but the mechanism of the beneficial action remains unexplained. After ingestion, a proportion of the drug is absorbed and reexcreted unchanged in the bile and also partly in the urine; the major step in metabolism is reductive cleavage of the azo-link releasing 5-amino-salicylic acid (5-ASA) and sulphapyridine (SP) which is a sulphonamide. The latter is absorbed almost completely from the colon and excreted in the urine after a variety of conjugation processes, while the 5-ASA is only partly absorbed and excreted in the urine after acetylation (Hanngren, Hansson, Svartz, and Ullberg, 1963; Schröder and Campbell, 1972). These metabolic pathways are essentially similar both in healthy subjects and in proctocolitis patients (Das, Eastwood, McManus, and Sircus, 1973). Experiments with germ-free animals have shown that the initial azo-link reduction takes place in the colon and depends on the presence of colonic bacteria (Peppercorn and Goldman, 1972; Schröder and Gustaffson, 1973), a finding supported by observations in ileostomized subjects (Schröder, Lewkonia,

${ }^{1}$ Requests for reprints should be sent to Dr R. Lendrum, Department of Gastroenterology, St Mary's Hospital, London W2 1 NY.

Received for publication 16 August 1974. and Price Evans, 1973) It remains unclear, however, whether unchanged SASP or the 5-ASA derivative are the active agents, possibly mediating their effect by local or systemic anti-inflammatory action, or whether the sulphapyridine component might be the

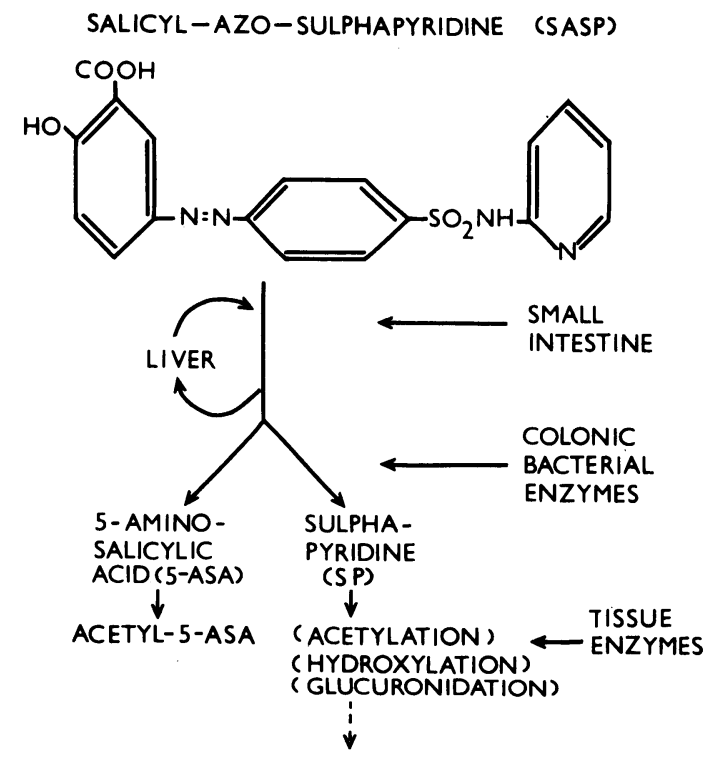

Fig 1 The metabolism of sulphasalazine after oral ingestion. An important step is reductive cleavage of the azo-link by colonic bacteria (derived from the data of Hanngren, Hansson, Svartz, and Ullberg, 1963;

Peppercorn and Goldman, 1972; Schröder, Lewkonia, and Price-Evans, 1973). 
more important, by means of a beneficial effect on colonic flora.

Published studies of the effects of SASP on the faecal flora have not demonstrated an antibacterial action. Indeed, Gorbach, Nahas, Plaut, Weinstein, Patterson, and Levitan (1968) found an overall increase in Gram-positive aerobes and in anaerobic lactobacilli in patients receiving the drug. Cooke (1969) concluded that there was little difference between the faecal flora of ulcerative colitis patients being treated with SASP and those not receiving this drug, although Clostridium welchii was isolated more frequently from the treated group. It is notable that in this study the anaerobe counts reported were lower than would be expected using really sensitive techniques. Drasar (1967) introduced exacting methods for anaerobe culture; it is now known that the strict anaerobes constitute more than $99 \%$ of the total viable faecal flora (Crowther, 1971).

Because of the conflicting and even paradoxical results of previous studies, and because improved techniques for anaerobe isolation are available, it seemed important to re-examine the possible effect of SASP on faecal flora in patients with inflammatory bowel disease.

\section{Patients}

Twenty-one patients were studied in whom proctocolitis had been diagnosed on clinical, radiological, and histological grounds. There were six males and 15 females aged 20-78 years. Two patients were first diagnosed within three months of study; the remainder had histories extending back between nine months and 24 years. Six of the patients had total colitis radiologically while the remainder had leftsided disease. At the time of study six patients were suffering from an acute exacerbation; only three were in complete clinical remission. Before this study, 11 patients had been taking SASP intermittently for periods between two months and 14 years. The dosage of SASP was $3 \mathrm{~g}$ daily except in five patients who were receiving 1-2 $\mathrm{g}$ daily because of side effects. Multiple stool samples were collected from each patient over periods up to 15 weeks. No samples were examined within two weeks of a change in SASP treatment. Thirteen patients received corticosteroids at some period during the study, as follows: oral prednisone, seven patients; parenteral ACTH, two patients; steroid enemas alone, four patients.

Five patients with Crohn's colitis diagnosed on rectal biopsy and radiology were also studied (three females, two males; aged 30-75 years); one also had terminal ileal involvement. The illness had been known to be present for between seven weeks and six years. Four of the patients were receiving oral corticosteroids and one of these also received SASP during the study. None of the 26 patients studied had dietary restriction or known dietary peculiarities.

\section{Bacteriological Studies}

Stool samples were brought to the hospital and within 12 hours a $0.5 \mathrm{ml}$ aliquot was diluted $1: 10$ in meat infusion broth (Lab-Lemco, Oxoid Ltd) containing $10 \%(\mathrm{v} / \mathrm{v})$ glycerol. These were immediately frozen and stored at $-70^{\circ} \mathrm{C}$. Laboratory procedures were carried out by the methods of Drasar and Crowther (1971) without knowledge of either the diagnosis or treatment. The organisms studied were the non-sporing anaerobic bacteria (mainly bacteroides, bifidobacteria, and eubacteria), the spore-forming anaerobes (clostridia) divided into two groups depending on whether or not they produced lecithinase, the $\mathrm{CO}_{2}$-requiring lactobacilli, and the aerobic organisms (principally oral and faecal streptococci and enterobacteria, usually Esch. coli).

For convenience of presentation the bacterial counts were expressed as $\log _{10}$ number of bacteria per millilitre faeces; where several samples were obtained while the patient was on the same treatment the mean $\log _{10}$ count was used in statistical analyses.

\section{Results}

COMPARISON OF PATIENTS WITH CROHN'S DISEASE AND PROCTOCOLITIS NOT RECEIVING SASP

Four patients with Crohn's colitis and six with idiopathic proctocolitis who did not receive SASP at any stage during the study were compared. The counts for both groups fell within the ranges obtained from a number of normal control subjects in other studies from this laboratory. No significant differences were found between the two groups (table I).

\begin{tabular}{|c|c|c|c|}
\hline Faecal Flora & $\begin{array}{l}\text { Normal } \\
\text { Subjects } \\
(n=68)\end{array}$ & $\begin{array}{l}\text { Crohn's } \\
\text { Disease } \\
(n=4)\end{array}$ & $\begin{array}{l}\text { Procto- } \\
\text { colitis } \\
(n=6)\end{array}$ \\
\hline $\begin{array}{l}\text { Total aerobes } \\
\text { Enterobacteria } \\
\text { Enterococci } \\
\text { Lactobacilli } \\
\text { Total non-sporing anaerobes } \\
\text { Opalescent-positive clostridia } \\
\text { Opalescent-negative clostridia }\end{array}$ & $\begin{array}{r}8 \cdot 0 \pm 1 \cdot 0 \\
7 \cdot 9 \pm 1 \cdot 3 \\
5 \cdot 8 \pm 1 \cdot 5 \\
6 \cdot 5 \pm 1 \cdot 8 \\
10 \cdot 1 \pm 0 \cdot 5 \\
4 \cdot 2 \pm 1 \cdot 8 \\
5 \cdot 7 \pm 1 \cdot 2\end{array}$ & $\begin{array}{l}8 \cdot 6 \pm 0 \cdot 3 \\
7 \cdot 9 \pm 1 \cdot 0 \\
6 \cdot 7 \pm 0 \cdot 2 \\
6 \cdot 2 \pm 1 \cdot 0 \\
9 \cdot 8 \pm 0 \cdot 2 \\
2 \cdot 4 \pm 1 \cdot 5 \\
5 \cdot 2 \pm 0 \cdot 7\end{array}$ & $\begin{array}{r}8 \cdot 4 \pm 0 \cdot 7 \\
7 \cdot 8 \pm 1 \cdot 2 \\
7 \cdot 1 \pm 1 \cdot 3 \\
5 \cdot 2 \pm 2 \cdot 8 \\
10 \cdot 0 \pm 0 \cdot 2 \\
3 \cdot 5 \pm 2 \cdot 4 \\
4 \cdot 3 \pm 2 \cdot 2\end{array}$ \\
\hline
\end{tabular}

Table I Comparison of faecal flora in Crohn's and proctocolitis patients not receiving SASP during the study

${ }^{1}$ Mean $\log _{10}$ bacterial counts per $\mathrm{ml}$ faeces \pm 1 SD. No statistically significant differences were found in any of these comparisons $(P>0.2)$. The faecal flora of normal English subjects described in studies on colon cancer are shown for comparison (Hill, Crowther, Drasar, Hawksworth, Aries, and Williams, 1971). 
EFFECT OF DISEASE ACTIVITY IN

\section{PROCTOCOLITIS PATIENTS}

The four patients with acute exacerbations of their illness showed large numbers of all the organisms studied compared with the 13 patients with less active disease (table II), considering only those who were not receiving SASP. It is notable that the largest difference in mean counts occurred in the opalescent-negative clostridia; no statistical significance was achieved in these differences, perhaps because of the small numbers involved.

\begin{tabular}{|c|c|c|}
\hline Faecal Flora & $\begin{array}{l}\text { Patients with Less } \\
\text { Active Disease } \\
(n=13)\end{array}$ & $\begin{array}{l}\text { Patients with } \\
\text { Acute } \\
\text { Exacerbation } \\
(n=4)\end{array}$ \\
\hline $\begin{array}{l}\text { Total aerobes } \\
\text { Enterobacteria } \\
\text { Enterococci } \\
\text { Lactobacilli } \\
\text { Total non-sporing anaerobes } \\
\text { Opalescent-positive clostridia } \\
\text { Opalescent-negative clostridia }\end{array}$ & $\begin{array}{l}8.2 \pm 1 \cdot 1 \\
7 \cdot 6 \pm 1 \cdot 4 \\
6.4 \pm 1 \cdot 8 \\
5.9 \pm 0.9 \\
9.9 \pm 0.4 \\
3 \cdot 2 \pm 2.4 \\
4.2 \pm 2.1\end{array}$ & $\begin{array}{r}8.6 \pm 0.8 \\
7.9 \pm 1.8 \\
7.4 \pm 1.1 \\
6.8 \pm 1.6 \\
10.1 \pm 0.4 \\
3.6 \pm 2.6 \\
5.8 \pm 0.7\end{array}$ \\
\hline
\end{tabular}

Table II Effect of disease activity on faecal flora in proctocolitis patients not receiving $S A S P^{1}$

${ }^{1} \log _{10}$ mean bacterial counts per $\mathrm{ml}$ faeces \pm 1 SD. No statistically significant differences were found in any of these comparisons $(\mathbf{P}>\mathbf{0} \cdot \mathbf{1})$

A COMPARISON OF PATIENTS RECEIVING SASP THROUGHOUT THE STUDY WITH THOSE NOT RECEIVING SASP AT ANY STAGE

Since no difference was demonstrable between the Crohn's and proctocolitis patients who did not receive SASP, it was possible to consider both groups together as cases of inflammatory bowel disease and to compare these 10 patients with five who had taken SASP throughout (table III). There were significantly fewer total aerobes in the SASP-treated patients $(t=2.28, P<0.05)$; this was largely due to a decrease in enterobacteria $(t=2.32, \quad P<0.05)$. Total anaerobes were also reduced in the treated

\begin{tabular}{llll}
\hline Faecal Flora & $\begin{array}{l}\text { Off SASP } \\
(n=10)\end{array}$ & $\begin{array}{l}\text { On SASP } \\
(n=5)\end{array}$ & $\begin{array}{l}\text { Significance } \\
\text { of } \\
\text { Difference }\end{array}$ \\
\hline Total aerobes & $8.5 \pm 0.6$ & $7.9 \pm 0.2$ & $\mathbf{P}<0.05$ \\
Enterobacteria & $7.8 \pm 1.0$ & $6.6 \pm 0.8$ & $\mathbf{P}<0.05$ \\
Enterococci & $7.0 \pm 1.0$ & $7.3 \pm 0.7$ & $\mathbf{P}>0.5$ \\
Lactobacilli & $5.6 \pm 2.2$ & $5.5 \pm 0.9$ & $\mathbf{P}>0.5$ \\
Total non-sporing anaerobes & $\mathbf{9 . 9} \pm \mathbf{0 . 2}$ & $\mathbf{9 . 1} \pm 0.1$ & $\mathbf{P}<0.001$ \\
Opalescent-positive clostridia & $3.1 \pm 2.1$ & $2.5 \pm 1.4$ & $\mathbf{P}>0.5$ \\
Opalescent-negative clostridia $4.7 \pm 1.7$ & $3.8 \pm 1.0$ & $\mathbf{P}>0.2$
\end{tabular}

Table III Comparison of patients taking SASP throughout the study with patients never receiving the drug ${ }^{1}$

${ }^{1} \log _{10}$ mean bacterial counts per $\mathrm{ml}$ faeces \pm 1 SD. group $(t=6.33, P<0.001)$. Although there were large differences in the mean counts of opalescentnegative clostridia, standard deviations were also large and the differences were not statistically significant $(t=1 \cdot 06, P>0 \cdot 2)$. Among those receiving SASP continuously were a patient with active Crohn's disease and another with an acute exacerbation of proctocolitis; both showed similar reductions in the numbers of these three groups of organisms to those observed in the patients with less active disease. Patients taking SASP continuously tended to have more frequent bowel actions than those not receiving SASP; three of the former group of five patients and only two of the latter group (10 patients) had three or more bowel actions daily.

THE EFFECT OF CHANGING SASP TREATMENT IN PATIENTS WITH PROCTOCOLITIS

During the study, in seven proctocolitis patients SASP therapy was discontinued while in four it was commenced. Thus, in all, 16 patients received SASP, while 21 patients did not do so, at some stage of the study. Figure 2 compares the mean $\log _{10}$ counts on and off SASP for each patient who changed this therapy. Reductions in the same three groups of organisms were found during SASP therapy as have been described above in patients who received the drug continually; paired $t$ tests showed significant reductions in enterobacteria $(t=2.53, P<0.05)$, total non-sporing anaerobes $(t=3 \cdot 18, \quad P<0.01)$, and opalescent-negative clostridia $(t=2 \cdot 49$, $P<0.05$ ). Three patients did not show consistent reductions in the numbers of all three organisms; one of these, who was receiving SASP in a dose of only 1 $g$ daily, showed a reduction in enterobacteria and total anaerobes but not in opalescent-negative clostridia; a second patient with left-sided colitis in complete remission showed a small increase in enterobacteria and a large increase in opalescentnegative clostridia while taking the drug; a third patient with total colitis and low-grade disease activity showed an increase in number of all three organisms during SASP treatment; both were receiving 3 g SASP daily. These three patients had only one bowel action daily, both during SASP therapy and after its cessation. Among the eight patients whose bacterial counts were lower while they were receiving SASP were four who had three or more bowel actions daily, two of whom had acute exacerbations; three of these had a decreased frequency of bowel action when sulphasalazine was given, while the fourth had no change of bowel habit on stopping the drug. The remaining four patients had one to two bowel actions daily whether or not SASP was being taken.

Considering only those patients who showed a 

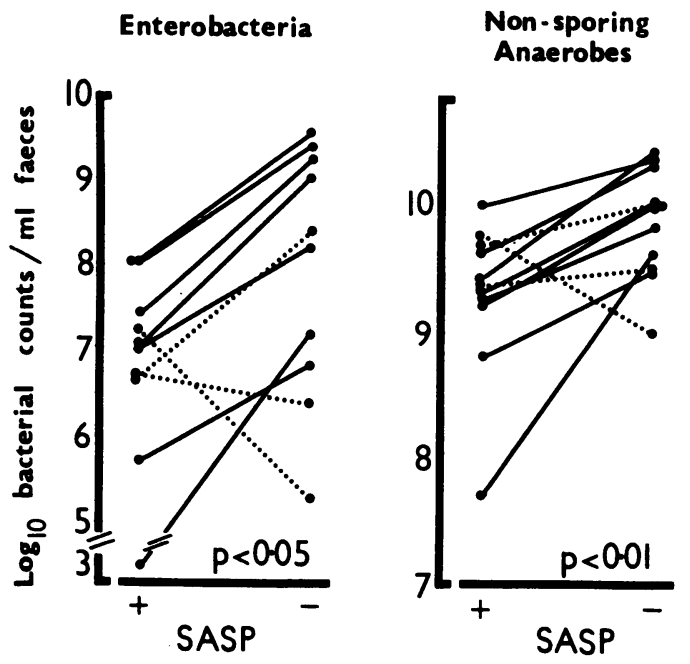

consistent change in all three groups of organisms the magnitude of the decrease while on SASP was 200-fold for opalescent-negative clostridia, 40-fold for enterobacteria, and 10-fold each for bacteroides and eubacteria. There were no significant alterations in counts of other organisms $(P>0 \cdot 2)$. Detailed examination of the total anaerobe population showed an almost equal reduction in each of the three main components-bacteroides, bifidobacteria, and eubacteria.

\section{EFFECTS OF STEROID THERAPY}

Table IV compares the mean $\log _{10}$ bacterial counts of proctocolitis patients receiving corticosteroid or ACTH treatment with those not doing so. Patients

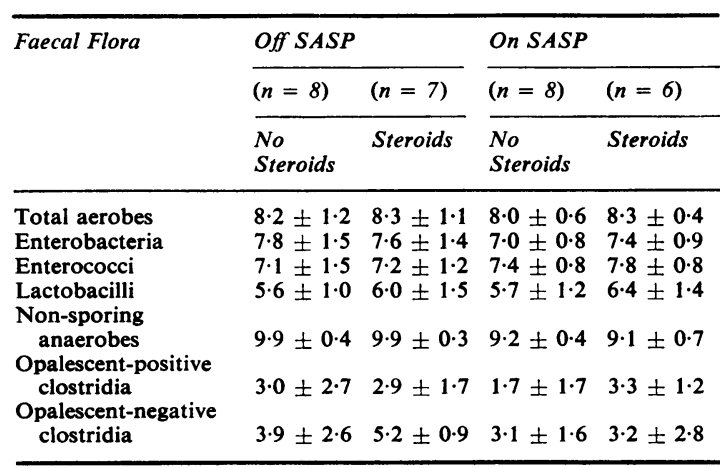

Table IV Effect of steroid therapy in patients treated with and without $S A S P^{1}$

${ }^{1} \log _{10}$ mean bacterial counts per $\mathrm{ml}$ faeces \pm 1 SD. No statistically significant differences were found (off SASP, P $>0.2$; on SASP, $P$ >> 0.05).

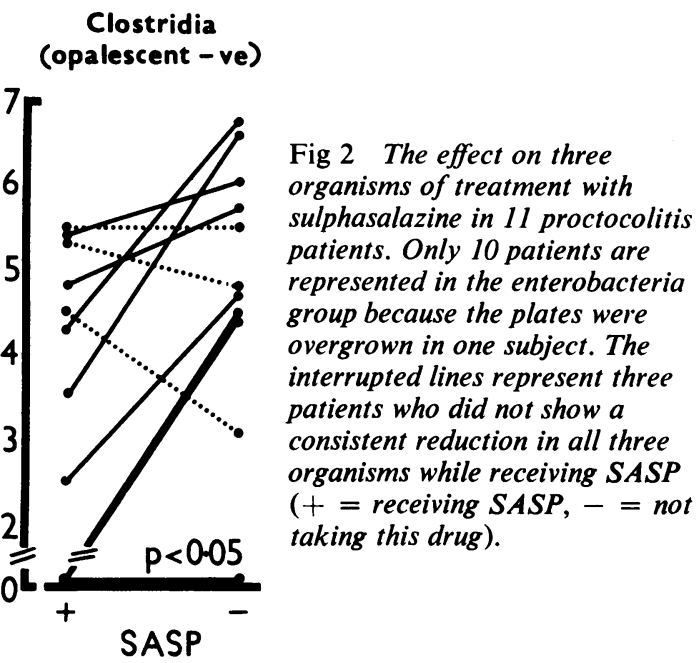

receiving SASP and those not receiving this drug are considered separately. No significant differences caused by corticosteroid therapy were found. Patients receiving predsol enemas only have been omitted from these comparisons.

\section{Discussion}

There are several possible mechanisms by which SASP, or its degradation products, might exert a beneficial effect in proctocolitis. Both SASP and 5-ASA have pronounced binding affinities for connective tissue (Hanngren et al, 1963), and may produce local anti-inflammatory effects. Sulphasalazine and salicylates have been shown to decrease prostaglandin synthesis, and, since the latter can produce diarrhoea, it is possible that some of the benefits of SASP result from this action (Butt, Collier, Gardiner, and Saeed, 1974). Salicyl-azosulphapyridine itself, having no free amino group, cannot act as a competitive inhibitor of para-aminobenzoic acid and so has no antibacterial effect comparable with that of the sulphonamide drugs. The release of a sulphonamide by azo-link cleavage, however, makes it possible for SASP to have an antibacterial effect. No such effect had been shown in the studies previously carried out.

This investigation has demonstrated a consistent decrease in the aerobic enterobacteria and in the non-sporing and sporing anaerobes in the majority of patients receiving SASP. It is likely that the sulphapyridine released by azo-link cleavage of SASP is responsible for this decrease. Since the colonic bacteria themselves bring about the azo-link cleavage 
it might be expected that those organisms which most actively do so would themselves be most reduced in number, because a locally high sulphapyridine concentration would occur. It is therefore of interest that some recent studies in vitro have shown lactobacilli and opalescent-negative clostridia to produce azo-link cleavage much more rapidly when compared with enterobacteria, enterococci, and non-sporing anaerobes (West and Hill, 1974). In the present study the opalescent-negative clostridia were numerically the most reduced; lactobacilli were not found to be reduced, but they are known to be able to utilize external sources of folate and so are sulphonamide resistant (Lampen and Jones, 1946). There is little information available on the sensitivity of clostridia or of the non-sporing anaerobic bacteria to sulphonamides but studies carried out by Drasar and Heaton (personal communication) indicate that approximately half of the strains of the four relevant genera (clostridia, bacteroides, bifidobacteria, and eubacteria) were sensitive when tested by the disc method against $100 \mu \mathrm{g}$ of sulphafurazole. It is likely that in the present studies there has been a selective killing of sulphonamide-sensitive organisms and in this respect it is noteworthy that Cooke, Ewins, Hywel-Jones, and Lennard-Jones (1974) found sulphapyridine-resistant $E$. coli more frequently in patients being treated with SASP.

No effect of corticosteroid therapy was demonstrated in this study; it is concluded that any observed changes in flora were caused by SASP rather than by steroid treatment.

The numbers of organisms found in patients with Crohn's colitis and with idiopathic proctocolitis who were not receiving SASP were similar, and fell within the ranges found in control patients derived from previous studies. Patients with active colitis tended to have increased numbers of all organisms studied when compared with those with less active disease, although these differences were not statistically significant. No particular organism can therefore be implicated as being of causal importance in active disease; the apparent increase in all organisms in active colitis patients may simply be a non-specific effect of diarrhoea (Weinstein, 1961). However, the patients receiving sulphasalazine throughout the present study who showed smaller numbers of organisms than those not receiving the drug had, by comparison, a slightly increased frequency of bowel actions. Three of the eight patients whose bacterial counts decreased during periods of SASP therapy had a concomitant improvement in bowel habit, while the other five did not. A simple decrease in diarrhoea does not therefore appear to explain the reduced numbers of organisms found during SASP therapy. In the three who responded atypically during SASP therapy in that they had an unchanged or increased count of enterobacteria, total non-sporing anaerobes, or opalescent-negative clostridia, no explanation for this difference was obvious. They did not appear to differ clinically from those patients whose flora decreased on sulphasalazine, and bowel habit was unchanged by this therapy. Gorbach et al (1968) found a significant increase in coliforms, but not in other organisms, in patients with active colitis and with regional enteritis, in contrast to the results described here. Increased numbers of haemolysin and necrotoxin-producing strains of $E$. coli have been found in proctocolitis (Cooke, 1968), and these strains appear to be significantly increased during relapses of the illness (Cooke et al, 1974); there was, however, no correlation between haemolysin production and sulphonamide resistance. The beneficial action of SASP could not be ascribed therefore to an effect on the $E$. coli component of faecal flora.

No conclusions about the possible aetiological significance of bacteria in proctocolitis can be drawn from the present investigation, since any antibacterial action of SASP found may be coincidental to its beneficial effects, the two phenomena occurring independently. However, the demonstration that a drug proven to be useful in the control of proctocolitis also reduces certain of the faecal microorganisms warrants further studies of the bacteria most affected, at different stages of disease activity. Those organisms which most actively metabolize SASP may prove to be especially important.

The authors are grateful to Mrs D. Irving, Department of Statistics, St Mary's Hospital, for helpful advice.

\section{References}

Baron, J. H., Connell, A. M., Lennard-Jones, J. E., and Avery Jones, F. (1962). Sulphasalazine and salicylazosulphadimidine in ulcerative colitis. Lancet, 1, 1094-1096.

Butt, A. A., Collier, H. O. J., Gardiner, P. J., and Saeed, S. A. (1974). Effects on prostaglandin biosynthesis of drugs affecting gastrointestinal function. Gut, 15, 344.

Cooke, E. M. (1968). Properties of strains of Escherichia coli isolated from the faeces of patients with ulcerative colitis, patients with acute diarrhoea and normal persons. J. Path. Bact., 95, 101-113.

Cooke, E. M. (1969). Faecal flora of patients with ulcerative colitis during treatment with salicylazosulphapyridine. Gut, 10, 565-568.

Cooke, E. M., Ewins, S. P., Hywel-Jones, J., and Lennard-Jones, J. E. (1974). Properties of strains of Escherichia coli carried in different phases of ulcerative colitis. Gut, 15, 143-146.

Crowther, J. S. (1971). Transport and storage of faeces for bacteriological examination. J. appl. Bact., 34, 477-483.

Das, K. M., Eastwood, M. A., McManus, J. P. A., and Sircus, W. (1973). The metabolism of salicylazosulphapyridine in ulcerative colitis. Gut, 14, 631-641.

Dick, A. P., Grayson, M. J., Carpenter, R. G., and Petrie, A. (1964). Controlled trial of sulphasalazine in the treatment of ulcerative colitis. Gut, 5, 437-442.

Dissanayake, A. S., and Truelove, S. C. (1973). A controlled therapeutic trial of long-term maintenance treatment of ulcerative colitis with sulphasalazine (salazopyrin). Gut. 14, 923-926. 
Drasar, B. S. (1967). Cultivation of anaerobic intestinal bacteria. J. Path. Bact., 94, 417-427.

Drasar, B. S., and Crowther, J. S. (1971). The cultivation of human intestinal bacteria. Soc. appl. Bact. techn. Ser., 5, 93-97.

Gorbach, S. L., Nahas, L., Plaut, A. G., Weinstein, L., Patterson, J. F., and Levitan, R. (1968). Studies of intestinal microflora. V. Fecal microbial ecology in ulcerative colitis and regional enteritis: relationship to severity of disease and chemotherapy. Gastroenterology, 54, 575-587.

Hanngren, A., Hansson, E., Svartz, N., and Ullberg, S. (1963). Distribution and metabolism of salicyl-azo-sulfapyridine. Acta med. scand., 173, 61-72.

Hill, M. J., Crowther, J. S., Drasar, B. S., Hawksworth, G., Aries, V., and Williams, R. E. O. (1971). Bacteria and aetiology of cancer of large bowel. Lancet, 1, 95-100.

Lampen, J. O., and Jones, M. J. (1946). The antagonism of sulphonamides by pteroyl glutamic acid and related compounds. J. biol. Chem., 164, 485-486.

Misiewicz, J. J., Lennard-Jones, J. E., Connell, A. M., Baron, J. H., and Avery Jones, F. (1965). Controlled trial of sulphasalazine in maintenance therapy for ulcerative colitis. Lancet, 1, 185-188.

Peppercorn, M. A., and Goldman, P. (1972). The role of intestinal bacteria in the metabolism of salicylazosulphapyridine. $J$. Pharmac. exp. Ther., 181, 555-562.

Schröder, H., and Campbell, D. E. S. (1972). Absorption, metabolism, and excretion of salicylazosulphapyridine in man. Clin. Pharmac. Ther., 13, 539-551.

Schröder, H., and Gustafsson, B. E. (1973). Azo reduction of salicylazosulphapyridine in germ-free and conventional rats. Xenobiotica 3, 225-231.

Schröder, H., Lewkonia, R. M., and Price-Evans, D. A. (1973) Metabolism of salicylazosulfapyridine in healthy subjects and in patients with ulcerative colitis. Clin. Pharmac. Ther., 14, 802-809.

Weinstein, L. (1961). Bacteriologic aspects of ulcerative colitis. Gastroenterology, 40, 323-330.

West, B., and Hill, M. J. (1974). In preparation. 